\title{
Corpo Ancestral: processo de criação do personagem Alboury no "Laboratório de Dramaturgismo e Direção Rotativa de Cenas"
}

\author{
Cuerpo Ancestral: proceso de creación del personaje Alboury em el \\ "Laboratório de Dramaturgismo e Direção Rotativa de Cenas"
}

\author{
Ancestral Body: creation process of Alboury character in the "Laboratório \\ de Dramaturgismo e Direção Rotativa de Cenas"
}

\author{
Lic. Marco Antônio Duarte ${ }^{1}$ \\ Ma. Maria Amélia Gimmler Netto² \\ Dra. Fernanda Vieira Fernandes ${ }^{3}$
}

\begin{abstract}
Resumo
Este trabalho pretende analisar o processo criativo de composição do personagem Alboury na montagem teatral Combate: corpos Mortos, vivos e por vir do "Laboratório de Dramaturgismo e Direção Rotativa de Cenas", orientado pela Prof. ${ }^{\text {a }}$ Dra. Fernanda Vieira Fernandes e Prof. ${ }^{a}$ Ma. Maria Amélia Gimmler Netto. A encenação parte do texto teatral Combate de negro e de cães, do autor francês Bernard-Marie Koltès, do livro Um útero é do tamanho de um punho, de Angélica Freitas, além de depoimentos dos artistas-criadores, canções, dados estatísticos e notícias atuais. A montagem ressalta relações de racismo por parte dos brancos ao principal personagem negro da peça, Alboury, e relações de machismo com a personagem Léone, única personagem feminina presente na peça. Considerando a questão histórica de mestiçagem no Brasil, composto também por africanos e índios, nesta montagem, a construção corporal e presença cênica do ator que interpreta Alboury tem como referenciais conceitos da religiosidade de matriz africana, em diálogo com o processo de direção da encenadora. Parte desta busca se detém às movimentações corporais das entidades de "Caboclos" vivenciadas pelo ator no Centro Espírita de Umbanda Caboclo Sete Estrelas, Pelotas/RS. Estes indivíduos viviam em comunidades, sua noção de coletividade e ancestralidade traçam o dialogismo com o personagem koltesiano. A representatividade do ator negro e seu personagem negro, ambos marginalizados em suas realidades, é também destacada neste texto, sob o viés das filosofias da religiosidade africana.
\end{abstract}

Palavras-Chave: Ancestralidade Negra; Criação de Personagem Teatral; Construção Corporal; Racismo.

1 (Discente do curso de Teatro Licenciatura - UFPel; Pelotas, Rio Grande do Sul, Brasil; marco.silva@ufpel.edu.br)

2 (Mestre em Artes Cênicas; Programa de Pós-graduação em Artes Cênicas - UFRGS; Porto Alegre, Rio Grande do Sul, Brasil; Docente do Curso de Teatro-Licenciatura - UFPel; Pelotas, Rio Grande do Sul, Brasil; mamelianetto@gmail.com)

3 (Doutora em Letras; Programa de Pós-graduação em Letras - UFRGS; Porto Alegre, Rio Grande do Sul, Brasil; Docente do Curso de Teatro-Licenciatura - UFPel; Pelotas, Rio Grande do Sul, Brasil; nvnandes@gmail.com) 

e-ISSN 2016/Atual: 2525-7870 | e-ISSN 2015/2016: 2447-018X

\title{
Resumen
}

Este trabajo se propone analizar el proceso de creación del personaje Alboury en la producción teatral "Combate: corpos mortos, vivos e por vir" del "Laboratório de Dramaturgismo e Direção Rotativa de Cenas", conducido por la Prof. ${ }^{a}$ Dra. Fernanda Vieira Fernandes y la Prof. ${ }^{a}$ Ma. María Amelia Gimmler Netto. La puesta en escena teatral del texto de Combate de Negro y Perros, del autor francés Bernard-Marie Koltès, el libro Um útero é do tamanho de um punho, de Angélica Freitas, así como testimonios de los artistas-creadores, canciones, estadísticas y noticias actuales. La puesta em escena presenta relaciones de racismo por parte de los personajes blancos al negro personaje principal de la obra, Alboury. También las relaciones de machismo para con Leone, que es el único personaje femenino en el juego. Teniendo en cuenta la cuestión histórica de la mezcla de razas en Brasil, compuesta por brancos, africanos y los indios, en este montaje teatral, la construcción del cuerpo y presencia del actor que juega el caracter Alboury tiene como referencia los conceptos de las religiones afro-brasileñas en el diálogo con la dirección del proceso de puesta em escena. Parte de esta búsqueda se detiene en los movimientos del cuerpo de las entidades de "caboclos" experimentados por el actor en el Centro Espiritual de Umbanda Caboclo Sete Estrelas, Pelotas / RS. Estas personas vivían en comunidades, su sentido de colectivo y la ascendencia traza el dialogismo com el caracter Alboury koltesiano. La representatividad del actor negro y su personaje negro negro, tanto uno como otro marginales en sus realidades, también se destaca en este texto, bajo la luz de las filosofías de la religiosidad africana.

Palabras claves: Ancestralidad Negra; Creación del Personaje Teatral; Construcción del Cuerpo; Racismo.

\begin{abstract}
This work intends to analyze the creative process of composition of the character Alboury in the play "Combate: corpos mortos, vivos e por vir" of the "Laboratorio de Dramaturgismo e direção Rotativa de Cenas", guided by Prof ${ }^{a}$. Phd. Fernanda Vieira Fernandes and Prof. ${ }^{a}$ Master Maria Amélia Gimmler Netto . The play is based on the french author Bernard-Marie Koltès theatrical text "Black Battles with Dogs", and on the Angélica Freitas book, "Um útero é do tamanho de um punho", as well as creator artists statements, songs, statistics data and current news. The play sows opressive relationship of racism by whites to the main black character of the play, Alboury, and relationship of male chauvinism with the Léone, the only female character is present in the play. Considering the historical miscegenation process in Brazil, composed by white, black and indigenous people, the body construction and scenic presence of the actor who interprets Alboury has as reference the concepts of the African's religiosity roots in this theatrical staging, and in dialogue with the director of scenes. Part of this research is limited to the entities of "Caboclos" corporal movements, experienced by the actor in the "Centro Espiritual de Umbanda Caboclo Sete Estrelas", Pelotas/RS. These individuals lived in communities, their notion of collectivity and ancestry traces a dialogism with the Koltesian character. The representation of the black actor and his black character, both marginalized in their realities, is also highlighted in this text, under the bias of the philosophies of African religiosity.
\end{abstract}

Keywords: Black Ancestry; Creation of Theatrical Character; Body Language; Racism.

\section{Introdução}

O presente relato de experiência de processo de criação em teatro tem como objetivo apresentar uma reflexão inicial sobre a composição do personagem Alboury, interpretado pelo ator Marco Antônio Duarte, na montagem teatral Combate: Corpos Mortos, Vivos e Por Vir. A montagem é fruto do processo criativo desenvolvido em laboratório e tem como tema as relações de opressão que perpassam os anos e que são presentes na sociedade contemporânea: o machismo e o racismo.

O "Laboratório de Dramaturgismo e Direção Rotativa de Cenas" foi fundado e orientado pelas professoras Maria Amélia Gimmler Netto e Fernanda Vieira Fernandes, ambas docentes do curso de Teatro-Licenciatura da Universidade Federal de Pelotas. Cada 
orientadora segue sua linha de pesquisa específica, que se complementam nas ações previstas para o experimento em laboratório. À linha da encenação se detém a professora Maria Amélia, como pesquisadora, na condução de grupo teatral, criação de cenas e no processo colaborativo de criação por meio da direção rotativa de cenas. A professora Fernanda Vieira Fernandes tem enfoque no papel do dramaturgista, responsável pela "criação dramatúrgica, poética da escrita teatral contemporânea e à eleição e estudo dos textos dramáticos levados ao grupo como estímulo ao processo criativo" (FERNANDES, 2016).

O laboratório tem como proposta contemplar não só discentes do Curso de Teatro Licenciatura, mas também professoras e estudantes egressos do mesmo como proposta de troca de experiências entre indivíduos e suas realidades no cenário teatral pelotense. A equipe de colaboradores da pesquisa foi integrada por artistas criadores, contendo quatro discentes do curso (Johann Ossanes, Juliana Caroline da Silva, Marco Antônio Duarte e Mario Celso Pereira Jr.), três estudantes egressos (Lucas Galho, Gabrielle Winck e Tatiana Duarte), além das duas professoras.

A criação do espetáculo parte do texto Combate de Negros e de Cães, de BernardMarie Koltès, com fragmentos do livro Um útero é do tamanho de um punho, de Angélica Freitas, e depoimentos dos artistas criadores sobre o que os conforta e desconforta, além de relatos pessoais dos artistas criadores envolvidos, de reportagens e dados estatísticos e de canções brasileiras foi o principal experimento realizado no laboratório.

\section{Princípios da criação do personagem Alboury na montagem de Combate: corpos mortos, vivos e por vir}

A linha de ação da peça acontece em um canteiro de obras francês, localizado em algum território africano, coordenado pelos franceses Horn, chefe de obras, e Cal, o engenheiro do canteiro. Os conflitos se iniciam a partir do aparecimento do único personagem negro do enredo, Alboury, que tem como intenção reivindicar o corpo do seu irmão desaparecido. Além da chegada de Léone ao canteiro, única personagem feminina da peça, é convidada por Horn a visitar a África e casar-se com o mesmo, porém sua presença causa outros conflitos entre os personagens que contrastam as relações de poder e opressão presentes na trama.

O início do processo de criação do personagem Alboury, que é foco desta reflexão, se deu a partir da cena "Desentendidos", um dos fragmentos da montagem em que acontece um diálogo entre as personagens Alboury e Léone. Em relação ao personagem Alboury, a encenadora propôs que o ator Marco Antônio Duarte criasse uma partitura corporal a partir da 
imagem da rocha como estímulo imagético de elemento da natureza e ponto de partida para a criação das movimentações do personagem. Após a criação da partitura individual foi proposto estímulo sensorial do vento, como segundo elemento da natureza, por meio de exercícios de contaminação de partituras corporais entre o ator em questão e a atriz Juliana Caroline, que representa Leone, única personagem feminina da peça.

Durante o decorrer do processo os artistas criadores Fernanda Fernandes e Lucas Galho propuseram ao elenco experimentar o treinamento corporal com base nas três energias distintas propostas por Arthur Lessac. Este artista pesquisador tinha como proposta desenvolver um treinamento vocal e corporal que pudesse explorar as potencialidades do corpo, chamado Kinesensic Training, processo sensorial que explora a descoberta e redescoberta das sensações do próprio corpo.

Dentre as três energias experimentadas no laboratório, como atividade de aquecimento corporal e estímulo para a criação de presença cênica para os atores, a primeira seria o estado energético Buoyancy, que explora a sensação de ausência de peso, como se o corpo fosse mais leve que o ar, energia relacionada à calma e a leveza. A segunda seria o estado de Radiancy, "caracterizada pela excitação vibradora do corpo, que pode ser ou mais sofisticada e sutil, como um contínuo tremor leve e suave, ou apresentar-se na forma elétrica da personificação da agilidade e destreza corporal." (OLIVEIRA, 2013, p.7) Já a terceira e última energia experimentada chama-se Potency, estado energético que é caracterizado pela potência muscular, em oposição à força bruta. A grande quantidade de oxigênio aumenta a força do corpo causando a sensação de intensidade muscular. A partir das três energias corporais experimentadas o ator optou por trabalhar com a construção do estado energético Potency, para alcançar uma potência muscular que complementasse a criação corporal de Alboury.

Entre diálogos com a dramaturgista e encenadora determinou-se a ideia de compor o personagem Alboury a partir de referências afrodescendentes, como proposta de interpretação e compreensão do personagem koltesiano e, ao mesmo tempo, assumir a brasilidade da montagem. Neste sentido a pesquisa se desempenhou a partir das experiências iniciais do ator, no processo de aprendizagem da capoeira Angola, orientado pelo instrutor Tatu (Cláudio Carle) e na sua experiência ritualística junto ao "Centro Espirita de Umbanda Caboclo Sete Estrelas" (Pelotas/RS) através de vivências corporais e observação dos arquétipos na manifestação ritualística da terreira.

A vontade de compreender o processo histórico de mestiçagem no Brasil "que é resultado das interações entre três matrizes culturais diferentes, a matriz indígena, a matriz europeia e a matriz africana" (JÚLIA, 2015, p.4) impulsionou a atividade criativa, pois este 
RELACult - Revista Latino-Americana de Estudos em Cultura e Sociedade

processo histórico compõem a formação da cultura do povo brasileiro. Aliada às experiências do ator no Centro de Umbanda acima citado, fez surgir a proposta, por parte do ator, de que o personagem Alboury fosse representado pelo arquétipo do Caboclo.

A escolha da representação do Caboclo da Umbanda tem a intenção de fazer um paralelo com a construção cultural do Brasil, que foi miscigenada, mas com foco nas manifestações afrodescendente e indígena. Através da tradição oral, forma principal como os ensinamentos da Umbanda são passados e aprendidos, conta-se que os Caboclos representam o "povo da mata", enviados pelo Orixá Oxossi, mas também se manifestam através de outros Orixás. Em algumas histórias os Caboclos são representados simbolicamente pelos descendentes da Cabocla Jurema, uma indígena guerreira. A partir de vivências corporais o ator envolvido selecionou os arquétipos do Caboclo Sete Estrelas, e do Caboclo Sete Flechas. Arquétipos adaptados pela criação do ator e orientação da encenadora, com atravessamentos de alguns golpes ou passos de capoeira, como o Rabo de Arraia e a base da ginga em três pontos de equilíbrio.

Para o ator, o personagem Alboury, na montagem de Combate: Corpos Mortos, Vivos e Por Vir, representa um corpo ancestral que carrega os ensinamentos de povos que foram e são discriminados e marginalizados. Representando a força e a resistência do negro/indígena perante o racismo implícito, institucional e seus mecanismos de genocídio.

\section{Considerações finais e novos horizontes}

A encenação Combate: Corpos Mortos, Vivos e Por Vir estreou em 15 e 16 de outubro de 2016 no Casarão 8 - Museu do Doce UFPel, da Praça Coronel Pedro Osório no centro de Pelotas, casarão histórico da cidade que foi construído por mãos negras e pertenceu a família Maciel, tradicional da cidade. A montagem concretiza um trabalho de um ano, desde o início da concepção do projeto entre as professoras responsáveis, passando pela formação do grupo e chegando aos encontros de estudos e criação.

O personagem Alboury carrega em si gestos e movimentações corporais que foram construídas, preservadas, reinventadas e transmitidas pela oralidade, que é uma característica da produção de conhecimento africana e indígena, por gerações através dos tempos. A montagem produzida explora um campo delicado que é propor uma discussão sobre o racismo e, como consequência, discutir também sobre a identidade negra brasileira e sobre os espaços do negro dentro do teatro e da sua história.

A composição do personagem aqui abordado foi um trabalho realizado dentro do processo criativo colaborativo do laboratório. Representa também, para o ator em questão, um 
ponto de partida para descobertas de outras poéticas e estéticas artísticas que tenham referências afro-indígenas brasileiras. Criações artísticas estas que podem possibilitar o anunciar e o enaltecer da diversidade das identidades brasileiras e que podem, também, contribuir para a melhor compreensão do teatro brasileiro contemporâneo. Assim como ampliar os conhecimentos e as possibilidades de reflexão do ator e de toda a equipe do laboratório descrito acima, a respeito das questões de negritude e de mestiçagem que compõe o povo brasileiro.

Para o ator, como homem negro, a construção de identidade se desenvolveu ao longo da vida. Não se nasce negro, se constrói para se tornar, pois segundo Munanga (1999), ser "branco" ou "negro" não são conceitos apenas biológicos, mas também sócio-políticos. O ator negro envolvido traça sua construção identitária, como proposta de ressaltar a sua identidade afro-indígena, reconhecendo as influências europeias, porém a identificação com esses povos vão além da cor da pele. As heranças deixadas pela oralidade constroem sua formação como um indivíduo no mundo, ator negro que constrói sua identidade e a reafirma a cada mergulho sobre a história e a cada experiência de vida.

\section{Referências}

ABREU, Luis A. Processo Colaborativo: Relato e Reflexões sobre uma Experiência de Criação. Cadernos da ELT, Santo André, n. 2, jun. 2004;

ARAUJO, Antonio. O processo colaborativo como modo de criação. in: Olhares

ESCH/Revista da Escola Superior de Artes Célia Helena. n 1.2009 ;

FERNANDES, F. V. O Personagem Negro na Literatura Drámatica Francesa do Século XX: La Putain Respectueuse, de Jean-Paul Sartre, e Combat de Nègre Et de Chiens, BernardMarie Koltès. Tese de Doutorado em Estudos de Literatura pelo Programa de Pós-Graduação em Letras da Universidade Federal do Rio Grande do Sul. 2014;

FERNANDES, F. V. Poética, concepção e composição da escrita dramática no "Laboratório de dramaturgismo e direção rotativa". Grupo de Estudos em Teatro: Histórias e Dramaturgias. Pró-Reitoria de Pesquisa. UFPel. 2016;

FISCHER, Estela. Processo colaborativo e experiências de companhias teatrais brasileiras. São Paulo: Hucitec, 2010;

FREITAS, Angélica. Um útero é do tamanho de um punho. São Paulo: Cosac \& Naif, 2013;

JÚLIA, F. Ancestralidade Em Cena - O Teatro do NATA. Repertório, Salvador, nº 24, p. 8697, 2015.1;

JÚNIOR, Barbosa Ademir. O livro essencial de Umbanda / Ademir Barbosa Júnior. - São Paulo: Universo dos Livros, 2014.

JURUÁ, Padrinho. "A Manifestação Do Espirito Para a Caridade" - O Que é Umbanda II Coletânea Umbanda. São Caetano do Sul, 20132500 p. Fundação Biblioteca Nacional 

e-ISSN 2016/Atual: 2525-7870 | e-ISSN 2015/2016: 2447-018X

Escritório de Direitos Autorais Certificado de Registro ou Averbação No Registro: 533.475 livro: 1024 - folha: 149

KOLTÈS, Bernard-Marie. Combate de negro e de cães, O retorno ao deserto e Tabataba. Edição bilíngue português-francês. Tradução para língua portuguesa de Ângela Leite Lopes. São Paulo: Aliança Francesa/Instituto Totem/Imprensa oficial do Estado de São Paulo, col. "Palco sur scène", 2010.

MOREIRA, C. M. G. Performances da memória e da resistência: a performance do caboclo nos rituais da umbanda. In: V Congresso Brasileiro de Pesquisa e Pós-Graduação em Artes Cênicas, 2008, Belo Horizonte. Anais do V Congresso Brasileiro de Pesquisa e PósGraduação em Artes Cênicas, 2008.

MUNANGA, Kabengele. Rediscutindo a mestiçagem no Brasil: identidade nacional versus identidade negra. Kabengele Munanga. Petrópolis, RJ: Vozes, 1999.

NASCIMENTO, A. Dramas para Negros e Prólogo para Brancos. Rio de Janeiro: TEN, 1961.

NASCIMENTO, A. Sortilégio II (Mistério Negro de Zumbi Redivivo). Rio de Janeiro: Paz e Terra, 1979. (Peça de teatro.)

NETTO, Maria Amélia Gimmler. Composição de Cenas e Condução de Grupo em Processo Colaborativo de Criação Teatral no "Laboratório de Dramaturgismo e Direção Rotativa". Grupo de Estudos e Pesquisas em Teatro, Educação e Práxis Social. Pró-Reitoria de Pesquisa. UFPel. 2016;

NICOLETE, Adélia. Criação coletiva e processo colaborativo: algumas semelhanças e diferenças no trabalho dramatúrgico. Revista Sala Preta. São Paulo: 2002, v. 2.

OLIVEIRA, M. R. T. Arthur Lessac: um ensaio sobre as energias corporais no treinamento do ator. Revista Brasileira de Estudos da Presença, Porto Alegre, v. 3, n. 2, p. 582-600, maio/ago. 2013. Disponível em: http://www.seer.ufrgs.br/presenca 